\title{
The value of 'writing retreats' in advancing innovative pedagogic research
}

\author{
Emma Coonan', Simon Pratt-Adams ${ }^{1}$, Mark Warnes ${ }^{2}$ \\ ${ }^{1}$ Centre for Innovation in Higher Education, Anglia Ruskin University, United Kingdom, \\ ${ }^{2}$ Anglia Learning \& Teaching, Anglia Ruskin University, United Kingdom.
}

\begin{abstract}
This paper outlines the work of the Centre for Innovation in Higher Education, which uses an educational laboratory model to advance the intersection of innovative research and teaching at Anglia Ruskin University (ARU). This evidence-based approach aims to promote active, reflective engagement with research in teaching and learning; foster collaborative and interdisciplinary inquiry into pedagogic practice; and support the development of a dynamic, sustainable pedagogic research community at ARU.

The Centre's work also increases the visibility and calibre of pedagogic research at national and international level. This paper describes a current research project being undertaken by researchers from the Centre and Anglia Learning \& Teaching which explores the longitudinal impact of its writing retreat provision on participants' writing practices and productivity, together with their perceptions of writing as a key element of the academic identity. This study is generating valuable original data about academics' writing practices and perceptions. It will contribute to the understanding of this important topic at a theoretical level, as well as outlining practical means through which universities can foster long-term academic writing productivity leading to enhanced research impact.
\end{abstract}

Keywords: writing retreats; academic writing; pedagogic research; interdisciplinary research; qualitative research; educational laboratory model 


\section{Introduction}

The Centre for Innovation in Higher Education was launched by Anglia Ruskin University (ARU) in July 2018 to advance the intersection between innovative educational research and pedagogic practice. ARU is a teaching-intensive university with strengths and distinctiveness in learning, teaching and assessment, and the Centre was created to enhance these strengths through applied research into teaching and learning; to make visible the impact of what ARU is already achieving in pedagogic excellence; and to foster new initiatives and further innovation in this area.

\subsection{An educational laboratory model}

The Centre employs an 'educational laboratory' model: that is, an active, collaborative and creative approach to pedagogic research. Key to this approach is the provision of opportunities for colleagues not merely to hear about excellent or innovative practice in teaching and learning, but to design, discuss, and reflect on those practices. The Centre runs various events throughout the year, all of which are designed to foster active and reflective engagement with aspects of pedagogic research, including seminars, an annual international conference, regular writing retreats, and monthly pedagogic research community meetings.

\subsection{Pedagogic research: the intersection of discipline knowledge and teaching practice}

Through its use of the educational laboratory model the Centre seeks to help colleagues bridge the gap between their own subject expertise and the practice of pedagogic research. Researchers accustomed to working within the methodological and epistemological frameworks of their discipline often experience difficulties in adapting to the thinking, practices and conventions of pedagogic research, which falls within the domain of the social sciences (Hutchings \& Shulman, 1999; O’Brien, 2008). They may be unfamiliar with the ethical requirements of conducting research with human subjects; with framing qualitative research questions rather than positing hypotheses; and with issues of rigour, reproducibility and generalisability in qualitative research (O’Brien, 2008).

Pedagogic research necessitates a dual disciplinary focus (Bennett \& Dewar, 2012; Coonan, 2019). Colleagues engaging in pedagogic research will be conducting an inquiry into the teaching or learning of their subject - be that Biochemistry, Law, Nursing, Construction, or any other subject domain in which major courses are taught. The object of the research is not to expand disciplinary knowledge, but to explore the means through which an understanding of that knowledge is supported and developed in students. This includes, for example, barriers to understanding that body of knowledge, and how they may be overcome through teaching; the "threshold concepts" or "troublesome knowledge" unique to the subject area (Meyer \& Land, 2005, p. 373); and the cognitive practices, conventions and 'ways of thinking' through which the knowledge is constituted and developed. 


\section{How the Centre supports colleagues engaged in pedagogic research}

The Centre has established a number of supported routes to engaging in pedagogic research in order to develop an active and sustainable community of practice at ARU.

\subsection{Advice and collaboration}

The Centre's research staff has a wide range of expertise that encompasses not only educational theory, practice and research design, but also academic writing practices, qualitative research methods, and the scholarly publishing landscape. They have created a number of resources to aid colleagues in developing a pedagogic research project, including designing research questions; collecting and analysing data; articulating the value and originality of the project; and the ethics of conducting pedagogic research. Where appropriate, the Centre can offer full collaboration on pedagogic research projects, with researchers from the Centre acting as co-investigators.

\subsection{Learning and Teaching Project Awards}

In addition to the provision of advice and collaborative opportunities, the Centre supports Anglia Learning \& Teaching in co-ordinating ARU's annual Learning and Teaching Project Awards (LTPA). These provide financial assistance for pedagogic research and offer the opportunity to conduct small-scale research projects over the course of each year to enrich and inform teaching practice and enhance the learning experience of ARU students.

Preliminary results of doctoral research into the impact of reward and recognition schemes on teaching excellence (Warnes, 2018) indicate that teaching fellowships (such as the National Teaching Fellowship scheme), are retrospective and only recognise teaching excellence once it has been achieved. In contrast, the primary focus of developmental programs, such as the LTPA scheme, is to support early career academics to develop both their research and teaching skills. Warnes (2018) reinforces this by suggesting that teaching fellowships have little or no impact on the student experience, since students are already benefiting from excellent teaching, while, conversely, the LTPA scheme may have an immediate impact, as action research projects evaluate and refine innovative pedagogic interventions.

\subsection{Strategic Projects}

The Centre also offers 15-week Strategic Project windows each semester which release Faculty staff from teaching, learning, assessment and administrative duties in order to engage in intensive, high-impact pedagogic research projects with fully funded support from the Centre. Projects to date have included research into digital credentialing of learners' interactions with curricular and co-curricular activities, and design thinking principles in module development. 


\subsection{The Pedagogic Research Community}

Through the educational laboratory model, manifested in the activities, events and research opportunities outlined above, the Centre works to foster a sustainable pedagogic research community engaged in ground-breaking teaching and learning at ARU.

The Community is sustained through regular monthly meetings, open to all staff engaged or interested in pedagogic research, and generally featuring speakers drawn from the community itself. These meetings are supplemented by a website containing an index of pedagogic research journals; a directory of staff engaged in pedagogic research at ARU; and a purpose-built online directory containing community's scholarly publications together with downloadable resources produced by the community to support teaching and students' learning. The impact of the Pedagogic Research Directory has been analysed using a mixed method approach (Pratt-Adams \& Warnes, 2018, manuscript submitted for publication). Findings indicate that use of the Directory is increasing and that members of the pedagogic research community use the resource in various ways, including showcasing their scholarly outputs and identifying collaborative opportunities with colleagues.

Most recently, researchers from the Centre have employed the educational laboratory model to design a research project exploring the impact of another of its flagship support initiatives, writing retreats. This original research is outlined in the next section.

\section{Longitudinal impact of writing retreats on participants' writing practices}

The Centre runs full-day Pedagogic Research Writing Retreats several times per year. These events offer intensive time for writing in company with others, with a light-touch structure designed to help participants maintain their focus, write productively, and develop effective writing strategies.

In January 2019 the Centre launched a research project to investigate the ongoing impact of attending a Writing Retreat on participants' writing practices and habits. This study investigates the writing practices of both academics and professional services colleagues, exploring how they move between disciplinary identities and construct new interdisciplinary voices through their pedagogic research writing.

\subsection{Study background}

Academic writing productivity is a crucial measure of impact for UK universities, unlocking research funding and contributing significantly to universities' status and reputation in an era of increased accountability measures. Writing retreats have become a popular means to increase universities’ published outputs (Murray \& Newton, 2009). 
Although evidence exists that writing retreats are an effective means of increasing academics' writing productivity (see e.g. Oermann, Nicoll, \& Block, 2014; Kornhaber, Cross, Betihavas, \& Bridgman, 2016), it is not well understood why this is the case (MacLeod, Steckley, \& Murray, 2012). However, MacLeod et al. (2012) assert that writing retreats enable the acquisition of writing strategies and the containment of anxiety, while Murray and Newton (2009) found that retreat participants reported changes in their approaches to writing and their awareness of their own identity as writers.

\subsection{Method}

The research is being conducted through analysis of existing evaluation forms together with up to 25 semi-structured interviews with colleagues who have attended a Pedagogic Research Writing Retreat. Interviews explore participants' anxieties, fears and confidence levels around writing; blockages experienced by participants, and solutions used to address them; the development of strategies to increase writing productivity and/or address anxieties; and how participants maintain (or not) a writing habit between retreats.

Interviewees are self-selecting, choosing to respond to a general invitation email sent by the Centre administrator, and the interview phase is ongoing. Analysis began on completion of the first interview, employing an emergent coding method (Saldaña, 2009). Ethical application was granted by ARU's Education Research Ethics Panel (protocol number ESCSREP-18-153).

\subsection{Preliminary findings}

Attendees are invited to completed evaluation forms at the end of each retreat. Responses show that the majority were able to achieve their intended purposes, which included a range of activities from planning and outlining papers, book/doctoral thesis chapters, and project proposals, to writing complete papers and articles.

Around $80 \%$ of attendees confirmed that they had learned new writing habits, including regular scheduling of writing time, planning the writing, taking breaks, and free writing. Benefits noted by attendees included:

Being forced to take a break(s) was useful: I came back refreshed

To keep writing without stopping to edit

Free writing. Plan - working to a plan. Timing

Planning writing. Thinking about using time effectively

Attendees particularly valued the peace and quiet of the retreat, in which it was possible to “Just sit quietly and get on with it!” In addition to feeling comfortable in the loose, but strictly enforced, structure, many attendees expressed their appreciation for having the Time: 
....and space

....away from constraints

...away from students, managers, teaching and emails

...to focus on writing without interruptions

...to undertake nothing but writing

...to write with peers who were doing the same

...out from the day job!

One particularly salient comment referred to the 'peer normalisation of writing up research'.

Following several requests for additional retreats, including a request from one attendee for "more regular retreats! Not necessarily all day or off site if this means they can happen more often”, the Centre has introduced informal, writing drop-in sessions, once per semester, in the evenings, on each of our two main campuses.

Building on the analysis of the evaluation forms, the semi-structured interviews have brought a number of new issues to the surface. Some participants demonstrated a very high level of reflexive awareness of their own writing habits, and extremely strategic approaches to managing the writing load. Notably, one interviewee (who had attended three retreats) employed a deeply nuanced extended metaphor to describe how they consciously manage their depth of engagement with each writing task:

I probably concentrated on something else for a bit - came up out of the depths of trying to, trying to write stuff to look at the structure [...] so I wasn't going down the same road. I came up, had another look at the map, and thought perhaps I can go down this bit here, look at that scenery for a bit ...

A valuable point that emerged early in our interviews was the need to move between research identities and voices, and the degree of ease with which this is effected. Participants attending a writing retreat are, necessarily, engaged in the practice and language of two fields: that of their 'home' discipline, and that of pedagogic research. Moving from one into the other is not always straightforward. One participant disclosed that:

I do find the language of getting into the pedagogy difficult, because I've come from a scientific background so [...] I feel like an alien.

The interviewee underlined this sense of unfamiliarity by comparing their pedagogic research writing to "going on a city break": a "just visiting” experience.

Although writing is not usually performed collaboratively at the retreats, the experience of sharing the writing space with others was perceived as a significant benefit by many 
participants, for a variety of reasons. These ranged from becoming aware of new practices and approaches - seeing other people's habits, that somehow they'll rub off on me and I'll be a better writer - to feelings of reassurance on perceiving others' practice:

I like to be around people that are also writing: that makes me feel like I'm on the right [...] route, on the right track

it [writing] can be messy, and that's OK.

The shared writing space can therefore offer a means of addressing writing anxiety, or as one interviewee put it, the "emotional stuff that's not actually the writing but is the stuff that kind of goes around the writing”.

\section{Conclusions}

Early findings from the study on the impact of pedagogic research writing retreats suggest that this strand of the support offered by the Centre is highly valued and makes a substantive contribution to writing productivity, not only at the level of actual output but in terms of participants' writing habits and practices, including the management of anxiety associated with writing.

The educational laboratory model employed by the Centre increases the visibility of ARU's pedagogic excellence and achievements, and supports new initiatives and further innovation in this area. It also increases the visibility and calibre of pedagogic research at national and international level through original research, including its inquiry into the longitudinal impact of writing retreats. In promoting the visibility and reach of pedagogic research and evidencing its value to scholarly knowledge, the Centre for Innovation in Higher Education enhances the reputation of pedagogic research not only at Anglia Ruskin University but nationally and internationally.

\section{References}

Bennett, C. D., \& Dewar, J. M. (2012). An Overview of the Scholarship of Teaching and Learning in Mathematics. PRIMUS, 22(6), 458-473. doi:10.1080/105119702011585389

Coonan, E. (2019). Inside/outside/in between: Librarians and SoTL research. In J. Belanger, M. Mallon, C. Bradley, R. Huisman, \& L. Hays (Eds.), The Grounded Instruction Librarian: participating in the scholarship of teaching and learning. Chicago: Association of College and Research Libraries.

Hutchings, P., \& Shulman, L. S. (1999). The scholarship of teaching: new elaborations, new directions. Change: The Magazine of Higher Learning, 31(5), 10-15. doi:10.1080/00091389909604218 
Kornhaber, R., Cross, M., Betihavas, V., \& Bridgman, H. (2016). The benefits and challenges of academic writing retreats: an integrative review. Higher Education Research \& Development, 35(6), 1210-1227. doi:10.1080/07294360.2016.1144572

MacLeod, I., Steckley, L., \& Murray, R. (2012). Time is not enough: Promoting strategic engagement with writing for publication. Studies in Higher Education, 37(6), 641-654. doi:10.1080/03075079.2010.527934

Meyer, J. H. F., \& Land, R. (2005). Threshold concepts and troublesome knowledge (2): Epistemological considerations and a conceptual framework for teaching and learning. Higher Education, 49(3), 373-388. https://doi.org/10.1007/s10734-004-6779-5

Murray, R., \& Newton, M. (2009). Writing retreat as structured intervention: Margin or mainstream? Higher Education Research and Development, 28(5), 541-553. doi:10.1080/07294360903154126

Oermann, M., Nicoll, L., \& Block, L. (2014). Long-term impact of an intensive writing retreat experience. Nursing Education Perspectives, 35(2), 134.

O’Brien, M. (2008). Navigating the SoTL Landscape: A Compass, Map and Some Tools for Getting Started. International Journal for the Scholarship of Teaching and Learning, 2(2). doi:10.20429/ijsotl.2008.020215

Pratt-Adams, S. \& Warnes, M. (2018). Impact of a Pedagogic Research Directory in one UK HE Institution. Manuscript submitted for publication.

Saldaña, J. (2009) The coding manual for qualitative researchers. London: Sage.

Warnes, M. (2018, July) An Exploration of the Possible Relationship between Reward and Recognition and Teaching Excellence in Higher Education. Paper presented at the Twelfth Annual Research Student Conference: Planning for the Future, Anglia Ruskin University (Chelmsford Campus), UK. 